\title{
ANALISIS PENDAPATAN USAHATANI POLA TANAM PADI-PADI DI DESA JEMBAYAN DALAM KECAMATAN LOA KULU KABUPATEN KUTAI KARTANEGARA
}

\section{(Analysis of Farming Income of Paddy-Paddy Cropping Patterns in Jembayan Dalam Village Loa Kulu District Kutai Kartanegara Regency)}

\author{
Nella Naomi Duakaju, Mariyah, dan Mutiara Caesar Aulia Ningrum \\ Jurusan/Program Studi Agribisnis, Fakultas Pertanian, Universitas Mulawarman \\ Kampus Gunung Kelua, Jl. Pasir Belengkong, Samarinda, Kalimantan Timur, Indonesia. 75123 \\ Penulis Koresponden: mutiaracaesar29@gmail.com;
}

Article Submitted : 16-12-2021

Article Accepted : 12-01-2022

\begin{abstract}
The agricultural sector plays an important role in people's daily food. Humans essentially need food crops as staples. The operation of a coal mining company around the area of Jembayan Dalam Village is claimed by farmers to pollute their fields and cause rice productivity to decline. Analyzes the income of farmers who perform a rice-rice crop rotation pattern in Jembayan Dalam Village, Loa Kulu District, Kutai Kartanegara Regency. The method used is the collection of data directly into the field by using Simple Random Sampling that 34 respondents then analyzed agricultural income with rice planting patterns on rice fields. Based on the results of research in Jembayan Dalam Village, Loa Kulu District, the average production cost in the growing season 1 is higher than the growing season 2 where in season 1 the average amount is

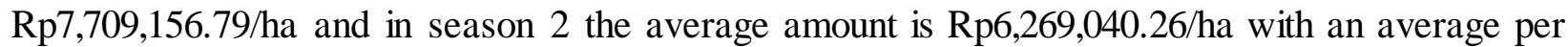
year of Rp13,978,197.04/ha. The average production on season 1 is higher than season 2 where the average season 1 is $1,393.24 \mathrm{~kg}$ and at season 2 the average is $642.35 \mathrm{~kg}$ with an annual average of $2,035.59 \mathrm{~kg}$. The average acceptance on season 1 is higher than season 2 where the average season 1 is Rp9,100,142.97/ha and on season 2 the average is Rp4,184,263.07/ha with an annual average of $\mathrm{Rp} 13,284,406.05 / \mathrm{ha}$. Average revenue on season 1 is higher than season 2 where on season 1 the average amount is Rp1,390,986.19 ha and on season 2 the average is Rp$2,448,492.87 /$ ha with an annual average of $\mathrm{Rp}-693,791.00 / \mathrm{ha}$.
\end{abstract}

Keywords: Food Crops, Production, Growing Season, Costs, Average

\section{PENDAHULUAN}

Sektor pertanian berperan penting dalam pangan masyarakat sehari-hari. Manusia pada hakekatnya membutuhkan tanaman pangan dan hortikultura sebagai bahan pokok. Indonesia dikenal sebagai negara yang sektor pertaniannya maju, namun hingga saat ini kita masih melakukan impor makanan pokok dari negara lain. Hal ini disebabkan adanya pertambahan jumlah penduduk, faktor alam, dan banyak lahan pertanian yang beralih fungsi ke lahan pertambangan. Menurut data BPS Indonesia (2018), bahwa pada tahun 2017 Nilai Impor Menurut Golongan Standart International Trade Classification (SITC) (Juta US\$) sebesar 156.985,5 dan pada tahun 2018 sebesar 188.711,4. Nilai Ekspor Menurut Golongan Standart International Trade Classification (SITC) (Juta US\$) pada tahun 2017 sebesar 168.828,2 dan pada tahun 2018 sebesar 180.012,7. Data ini menunjukkan 
bahwa terjadi peningkatan nilai impor sebanyak 31.725,9 Juta US\$.

Menurut data BPS yang diperoleh dari Survei Kerangka Sampel Area, Kalimantan Timur menghasilkan 253.818,37 ton padi pada tahun 2019 dan 262.855,55 ton padi pada tahun 2020. Adanya adanya peningkatan produksi tersebut didukung pertambahan luas panen. Berdasarkan data luas panen diperoleh luas sebesar $69.707,75$ hektar pada tahun 2019 dan 72.252,78 hektar pada tahun 2020. Kabupaten Kutai Kartanegara masih menjadi produsen padi tertinggi di Kalimantan Timur bila ditinjau berdasarkan kabupaten/kota di Kalimantan Timur dengan produksi padi sebesar $119.318,88$ ton. Luas panen padi di Kabupaten Kutai Kartanegara sebesar 32.214,63 hektar, atau 46 persen dari luas panen padi di seluruh Kalimantan Timur. Produksi beras di Kalimantan Timur berbanding lurus dengan produksi padinya. Beras yang dihasilkan dari 262.855,55 ton padi sebesar 152.107,09 ton di Kalimantan Timur pada tahun 2020. Nilai produksi ini meningkat bila dibandingkan dengan produksi beras tahun 2019 sebesar 146.877,61 ton beras, yang dihasilkan dari 253.818,37 ton padi (BPS Provinsi Kalimantan Timur, 2021).

Kondisi sektor pertanian di Desa Jembayan Dalam, Kecamatan Loa Kulu, Kabupaten Kutai Kartanegara yang dekat dengan aktivitas perusahaan tambang batu bara yaitu PT.MHU. Hutan yang gundul karena pembukaan lahan pertambangan dan sebagian besar wilayah masih berupa semak belukar yang belum termanfaatkan untuk kegiatan produktif menyebabkan penyerapan air hujan tidak maksimal. Ketika musim hujan datang maka sawah petani tergenang air. Sebaliknya, ketika musim kemarau datang maka sawah kering. Sebagian dari lahan pertanian tidak bisa digunakan karena adanya limbah perusahaan batu bara yang mencemari air dan saluran irigasi. Hal ini menyebabkan produksi tanaman pertanian tidak maksimal karena ketersediaan air yang semakin berkurang.

Hasil penelitian yang dilaporkan oleh S et al., (2020) bahwa di Desa Kerta Buana, Kecamatan Tenggarong Seberang terdapat perbedaan pendapatan usahatani padi sawah sekitar tambang yaitu Rp3.657.662,22 $\mathrm{mt}^{-1}$ (R/C sebesar 1,37) sedangkan pendapatan usahatani padi sawah bukan sekitar tambang sebesar Rp9.469.930,33 $\mathrm{mt}^{-1}$ (R/C sebesar 1,74). yang ada di Desa Kerta Buana Kecamatan Tenggarong Seberang.

Produksi yang rendah dapat menurunkan pendapatan petani, khususnya pendapatan rumah tangga atau keluarga sehingga petani kesulitan dalam memenuhi kebutuhan hidup sehari-hari. Berdasarkan RPJM Desa Jembayan Dalam tahun 2018, sebagian besar penduduk bermatapencaharian sebagai buruh tani $(22,00 \%)$, petani $(18,25 \%)$, pekerja perusahaan $(20,57 \%)$ dari 480 penduduk yang terdata. Hal ini menunjukkan sebagian masyarakat Desa Jembayan Dalam bekerja di bidang pertanian untuk memenuhi kebutuhan sehari-hari.

Perlakuan pola tanam pada usahatani dapat meningkatkan produksi, yang akhirnya dapat meningkatkan pendapatan petani, karena dengan cara tersebut petani dapat mengelola usahatani dengan lahan pertanian yang terbatas (Saninov et al., 2012). Selain perbaikan pola tanam, pengendalian hamapenyakit perlu juga diperhatikan agar produksi dalam maksimal hal ini berpengaruh terhadap pendapatan usahatani.

Kegiatan pertanian di Desa Jembayan berjalan dengan baik mengingat bahwa sebagian mata pencaharian masyarakat desa adalah petani dan sebagian lahannya masih berupa lahan pertanian karena letaknya di pedesaan. Kehadiran perusahaan tambang di dekat desa Jembayan Dalam membuat sebagian lahan pertanian tidak dapat digunakan dengan baik karena limbah perusahaan tambang mengalir di dekat saluran irigasi dan pengairan petani di desa ini masih menggunakan tadah hujan. 
Komoditas yang dominan diusahakan oleh petani di Desa Jembayan Dalam yaitu padi sawah. Berdasarkan informasi dan data pendahuluan, usahatani padi sawah di lokasi ini umumnya dilakukan dengan frekuensi tanam 2 kali setahun. Pola tanam yang sering dilakukan adalah padi-padi. Petani kesulitan dalam mengakses bantuan pupuk bersubsidi karena kurangnya ketersediaan pupuk bersubsidi yang ada di desa tersebut. Beberapa petani padi di desa Jembayan Dalam mengalami gagal panen, salah satu faktor tersebut dikarenakan penyakit kuning atau penyakit blas yang menimbulkan bercak coklat pada daun dan tangkai malai.

\section{METODE PENELITIAN}

Penelitian ini dilaksanakan dari bulan April sampai Juni 2021 di Desa Jembayan Dalam, Kecamatan Loa Kulu, Kabupaten Kutai Kartanegara Kalimantan Timur.

Teknik penentuan responden petani dalam penelitian ini menggunakan metode Simple Random sampling. Jumlah presisi akan ditentukan sebesar $15 \%$. Menurut Munawaroh (2015), dalam menentukan banyaknya sampel dalam penelitian yang dapat mewakili populasi yaitu tingkat baku yang menyesuaikan dengan kesanggupan, tenaga, biaya dan ketersediaan waktu, sehingga peneliti memutuskan untuk menggunakan jumlah presisi sebesar $15 \%$. Berdasarkan profil Desa Jembayan Dalam 2020, terdata sebanyak 149 orang petani.

Menurut Salminah (2018) bahwa untuk menghitung besaran sampel dapat menggunakan rumus yaitu :

Keterangan:

$$
n=\frac{N}{N(d)^{2}+1}
$$

$\mathrm{N}$ = banyaknya sampel yang akan diamb

$\mathrm{N}=$ populasi petani padi

$\mathrm{D}=$ tingkat presisi $(15 \%)$

Maka diperoleh sampel sebagai berikut:

$$
n=\frac{149}{149(0,15)^{2}+1}
$$

$$
\begin{gathered}
n=\frac{149}{149(0,0225)+1} \\
n=\frac{149}{4,3525} \\
n=34,2331 \\
n=34
\end{gathered}
$$

Maka diperoleh 34 orang petani padi sawah yang akan dijadikan sebagai sampel oleh peneliti.

\section{HASIL DAN PEMBAHASAN}

\section{Usahatani Padi Sawah Di Desa Jembayan}

Kegiatan petani padi sawah di Desa Jembayan Dalam dijalankan untuk kebutuhan pokok sehari-hari dan dijual. Sebelum adanya aktivitas tambang, kegiatan usahatani dilakukan sebanyak tiga kali musim tanam dalam setahun. Selama 3 tahun terakhir, kegiatan usahatani padi sawah dilakukan sebanyak dua kali musim tanam dalam satu tahun. Petani padi sawah di desa ini menanam berbagai jenis benih padi sawah, antara lain IR 64, Serang, Mekongga, dan Ciherang. Desa Jembayan Dalam dikenal sebagai desa penghasil padi sawah di Kecamatan Loa Kulu karena lahan pertaniannya yang luas.

Terdapat beberapa tahapan usahatani padi sawah, antara lain :

a. Pengolahan lahan

Pengolahan lahan dengan cara manual yaitu membersihkan tanaman atau gulma yang masih tersisa dengan menggunakan alat tradisional seperti cangkul, arit, dan parang. Setelah itu petani dapat menggunakan mesin traktor agar hasil lebih maksimal.

b. Penanaman

Benih yang digunakan oleh petani di Desa Jembayan Dalam rata-rata berasal dari hasil panen padi sebelumnya, jadi petani tidak mengeluarkan biaya untuk membeli benih. Lamanya penanaman tergantung dari luas lahan dan tenaga kerja yang digunakan, yaitu antara dua hari sampai dengan lima hari. 


\section{c. Pengairan}

Petani di Desa Jembayan Dalam masih mengandalkan sistem pengairan dengan air tadah hujan, yaitu dengan membuat tampungan parit kecil sehingga dapat digunakan ketika cuaca memasuki musim kemarau.

\section{d. Pemupukan}

Petani biasanya melakukan pemupukan secara bertahap dalam satu musim tanam yaitu antara dua sampai tiga kali. Pemupukan pertama dimulai ketika benih padi berumur 10 hari, kedua saat padi berumur 21 hari, dan ketiga saat padi berumur 45 hari.

e. Penyiangan, Penyulaman, dan

Pengendalian HPT

Penyiangan dilakukan dengan mencabut gulma yang tumbuh di sela-sela tanaman padi dengan tangan atau bantuan arit, untuk gulma yang sulit dicabut menyemprotkan herbisida yaitu ketika padi berumur \pm 20 hari setelah tanam dan kedua ketika padi berumur 45-50 hari setelah tanam.

Penyulaman dilakukan ketika benih 7-14 hari setelah, dan pengendalian hama penyakit dilakukan satu atau dua hari sekali dengan menggunakan pestisida.

\section{f. Pemanenan}

Tanaman padi dapat dipanen dengan menggunakan arit apabila sudah berumur antara 115-120 hari saat butiran berwarna kuning tua. Padi yang sudah dipanen dapat dirontokkan dengan alat perontok padi atau dengan cara manual. Setelah itu padi dijemur langsung terkena matahari selama satu hingga tiga hari agar padi bagus dan tahan lama. Kemudian gabah yang sudah kering dapat langsung dikemas ke dalam karung.

\section{Pola Tanam}

Pola tanam dapat mempengaruhi usahatani petani, yaitu dengan beragam jenis tanaman yang ditanam maka pendapatan yang diperoleh dapat melalui 2 atau lebih jenis tanaman dalam satu tahun.

Pola tanam yang digunakan adalah sistem monokultur dengan pola tanam padi- padi. Ada beberapa faktor petani tidak bisa mengatur pola tanam seperti petani di desa lain, salah satunya karena pengairan yang sulit dan tekstur tanah lampung yang kurang baik untuk tanaman. Masalah yang dihadapi oleh petani yaitu hama dan penyakit pada tanaman padi serta gagal panen. Penggunaan pola tanam pada musim 1 ke musim 2 tetap. Jenis varietas padi sawah yang diusahakan antara lain varietas IR 64, Serang, Mekongga, dan Ciherang. Pola tanam pada musim tanam 1 dimulai pada bulan JuniSeptember. Lahan sawah pada bulan Oktober-November lahan tidak ditanami oleh tanaman lain. Pola tanam pada musim tanam 2 dimulai pada bulan DesemberMaret. Pada bulan April-Mei lahan tidak ditanam tanaman lain.

Menurut hasil penelitian yang dilaporkan Yunanda et al., (2013) bahwa satu-satunya faktor perlakuan komoditi memiliki pengaruh yang signifikan terhadap jumlah malai per rumpun saat panen. Komoditi IR64 menghasilkan 8 malai per rumpun, lebih banyak dari komoditi Jatiluhur dengan 3 malai per rumpun.

Selanjutnya dilaporkan oleh Hambali dan Lubis (2015) bahwa kemampuan membentuk anakan tiap varietas berbedabeda. Varietas Unggul Baru (VUB) seperti Inpari 13, Ciherang, Mekongga mampu membentuk anakan berganda dengan ratarata yaitu 17,23; 16,70; dan 19,40 anakan.

\section{Biaya Produksi}

Berdasarkan hasil penelitian menunjukkan bahwa besaran biaya produksi (biaya tetap dan biaya variabel) antara musim tanam ke-1 dan musim tanam ke-2 berbeda. Biaya produksi dengan pola tanam padi-padi pada musim tanam ke-1 dari bulan Juni-September dengan rata-rata sebesar $\mathrm{Rp}$ 7.709.156,79/ha/mt, sedangkan biaya produksi pada musim tanam ke-2 dari bulan Desember-Maret dengan rata-rata biaya $\mathrm{Rp}$ $6.080 .577,02 / \mathrm{ha} / \mathrm{mt}$. Biaya produksi per tahun dengan rata-rata sebesar $\mathrm{Rp}$ 13.789.733,81/ha/thn. 
Biaya total meliputi biaya sewa lahan, biaya sewa traktor, biaya penyusutan alat, biaya benih, biaya pupuk, biaya pestisida, dan biaya tenaga kerja yang dikeluarkan pada musim tanam ke-1 adalah lebih besar dibanding musim tanam ke-2.Hal ini dipengaruhi faktor penggunaan input maupun harga input. Penggunaan input meliputi penggunaan benih yang bervariasi, penggunaan pupuk, penggunaan pestisida, tenaga kerja, dan biaya lain-lain. Seperti dinyatakan oleh Indah et al., (2015) bahwa salah satu faktor produksi yang berperan dalam meningkatkan produksi padi yaitu benih. Upaya peningkatan produksi akan berhasil jika benih yang berkualitas baik tersedia dan dalam jumlah yang cukup sekitar $20-25 \mathrm{~kg} / \mathrm{ha}$.

Pada MT 1, Varietas IR 64, Serang, dan Ciherang melebihi anjuran yang telah ditetapkan. Rata-rata penggunaan benih pada MT 1 dengan varietas IR 64 sebesar 58,04 $\mathrm{kg} / \mathrm{ha}$, varietas Serang sebesar $61,50 \mathrm{~kg} / \mathrm{ha}$, varietas Mekongga sebesar 20,00 kg/ha, dan varietas Ciherang sebesar 62,00 kg/ha.

Pada MT 2, Varietas IR 64, Serang, dan Ciherang melebihi anjuran yang telah ditetapkan. Rata-rata penggunaan benih pada MT 2 dengan varietas IR 64 sebesar 28,82 $\mathrm{kg} / \mathrm{ha}$, varietas Serang sebesar $33,00 \mathrm{~kg} / \mathrm{ha}$, varietas Mekongga sebesar 15,00 kg/ha, dan varietas Ciherang sebesar $31,00 \mathrm{~kg} / \mathrm{ha}$.

Tabel 1. Rincian Rata-Rata Pengunaan Benih Padi Pola Tanam Padi-Padi

\begin{tabular}{cccc}
\hline \multirow{2}{*}{ Jenis Benih } & MT 1 & MT 2 & \\
\cline { 2 - 3 } & $\begin{array}{c}\text { Rata-rata } \\
\text { Penggunaan }(\mathrm{kg})\end{array}$ & Rata-rata Penggunaan $(\mathrm{kg})$ & \\
& 58,04 & 28,82 & $440.191,33$ \\
IR 64 & 61,50 & 33,00 & $820.909,09$ \\
Serang & 20,00 & 15,00 & $490.000,00$ \\
Mekongga & 62,00 & 31,00 & $630.000,00$ \\
Ciherang & &
\end{tabular}

Sumber : Data Primer (diolah), 2021

Sistem tanam yang dilakukan petani adalah tanam benih langsung atau Tabela, penggunaan benih di areal persawahan sekitar tambang dilakukan oleh petani dua kali lebih dari anjuran benih yang disarankan untuk menghindari resiko benih padi yang tidak tumbuh.

Pada umur pembungaan Tabela, pembungaan rata-rata 3-9 hari lebih cepat dibandingkan perlakuan umur semai lain yang ditanam dengan sistem tanam pindah. Di sisi lain, Tabela panen rata-rata 12 hari lebih cepat daripada sistem tanam pindah. Pembungaan dan pemanenan yang cepat pada sistem Tabela biasanya disebabkan oleh benih yang langsung disemai tanpa membiarkan tanaman tergenang air, sedangkan pada sistem tanam pindah dapat dibiarkan dengan biji selama pemisahan benih, sehingga membutuhkan waktu untuk tumbuh setelah tanam. Hal ini dapat memperpanjang umur tanaman (Usman et al., 2014).

\section{Produksi}

Ada perbedaan besaran produksi, yaitu produksi pada MT ke-1 lebih besar dari produksi pada MT ke-2. Rata-rata produksi padi pada MT ke-1 yaitu 1.393,24 kg, sedangkan MT ke-2 hanya sebesar 642,35 $\mathrm{kg}$ dengan rata-rata produksi per tahun $2.035,59 \mathrm{~kg}$. Produksi padi pada saat MT ke 2 lebih rendah dari MT ke 1 karena curah hujan yang terbatas dan sistem pengairan padi yang bergantung pada tadah hujan, sehingga penggunaan faktor produksi seperti penggunaan benih, pupuk, dan pestisida menjadi tidak efektif, sehingga produktivitas dan pendapatan usahatani padi sawah rendah. 
Produksi padi sawah yang mengalami dampak dari limbah batu bara yang mengalir ke beberapa area sawah petani mengakibatkan $\mathrm{pH}$ tanah yang rendah sehingga unsur hara pada tanah berkurang dan proses perkembangan tanaman yang tidak maksimal sehingga petani menggunakan input lebih banyak dibandingkan petani yang tidak berada di sekitar tambang batu bara.

\section{Penerimaan}

Berdasarkan data hasil penelitian menunjukkan bahwa penerimaan yang diperoleh petani pada MT ke 1 rata-rata sebesar Rp 9.100.142,97/ha, sedangkan penerimaan pada MT ke 2 rata-rata sebesar Rp 4.184.263,07/ha. Berikut rincian rata-rata penerimaan usahatani padi sawah pola padipadi (Tabel 2).

Tabel 2. Rincian Rata-Rata Penerimaan Usahatani Padi Sawah Pola Padi-Padi

\begin{tabular}{lcc}
\hline \multicolumn{1}{c}{ Uraian } & Musim Tanam 1 & Musim Tanam 2 \\
\hline Produksi (kg) & $1.393,24$ & 642,35 \\
Harga (Rp/kg) & $4.991,18$ & $4.788,24$ \\
Penerimaan (Rp/ha) & $9.100 .142,97$ & $4.184 .263,07$ \\
\hline
\end{tabular}

Sumber : Data Primer (diolah), 2021

Penerimaan yang diperoleh antara MT ke-1 dan MT ke-2 berbeda. Penerimaan yang diperoleh petani dengan pola padi-padi pada MT ke-1 rata-rata sebesar $\mathrm{Rp}$ 9.100.142,97/ha, sedangkan pada MT ke-2 rata-rata penerimaan sebesar $\mathrm{Rp}$ 4.184.263,07/ha dengan rata-rata penerimaan per tahun sebesar Rp13.284.406,05/ha/thn. Banyaknya penerimaan yang dihasilkan oleh masingmasing petani tergantung pada hasil panen yang diperoleh. Penggunaan input seperti benih, pupuk, pestisida, tenaga kerja dan biaya lain-lain dapat berpengaruh pada output yang dihasilkan. Penggunaan benih, pupuk dan pestisida yang baik dan tepat dengan anjuran dapat meningkatkan kualitas output yang dihasilkan sehingga petani dapat membuat harga output yang sesuai dengan tingkat harga beras di pasaran.

Perbedaan hasil gabah antar musim untuk tanaman padi sangat kompleks di bawah pengaruh faktor genetik dan lingkungan seperti teknik budidaya, kondisi cuaca, dan potensi serangan hama atau penyakit. Untuk hasil terbaik, perlu memetakan kondisi khusus untuk setiap musim (Satoto et al., 2013).

\section{Pendapatan}

Pendapatan dengan pola tanam padipadi pada MT ke-1 (Juni sampai September) rata-rata sebesar Rp1.390.986,19/ha/mt, sedangkan pendapatan pada MT ke-2 (Desember sampai Maret) rata-rata sebesar Rp-2.260.029,63/ha/mt.Rata-rata pendapatan per tahun padi sawah yaitu sebesar Rp505.327,76/ha/thn (Tabel 3).

Tabel 3. Rincian Rata-Rata Pendapatan Usahatani Padi Sawah Pola Padi-Padi

\begin{tabular}{lcc}
\hline \multirow{2}{*}{ Uraian } & Musim Tanam 1 & Musim Tanam 2 \\
\cline { 2 - 3 } & Nilai (Rp/ha) & Nilai (Rp/ha) \\
\hline Penerimaan & $9.100 .142,97$ & $4.639 .236,11$ \\
Biaya tetap & $1.474 .810,61$ & $1.474 .810,61$ \\
Biaya variabel & $6.234 .346,18$ & $4.605 .766,41$ \\
Total Biaya & $7.709 .156,79$ & $6.080 .577,02$ \\
Pendapatan & $1.390 .986,19$ & $-2.260 .029,63$ \\
\hline
\end{tabular}

Sumber : Data Primer (diolah), 2021 
Biaya produksi dapat mempengaruhi pendapatan yang diperoleh petani, pendapatan MT ke 1 yang diperoleh lebih besar dibandingkan pendapatan pada MT ke 2. Tingginya pendapatan tersebut karena penerimaan padi pada MT ke 1 per hektar lebih besar daripada penerimaan padi pada MT ke 2. Produksi padi pada MT ke 1 lebih tinggi daripada produksi MT ke 2 karena adanya faktor hama dan penyakit pada tanaman padi. Biaya produksi yang dikeluarkan oleh petani, biaya total pada MT ke 1 lebih besar daripada pada MT ke 2 . Maka dari itu, karena penerimaan pada MT 1 lebih besar, sehingga pendapatan pada MT 1 juga lebih besar.

Faktor eksternal dalam usahatani yang dapat mempengaruhi output yang dihasilkan antara lain faktor cuaca, pengairan lahan, dan serangan hama-penyakit (HPT). Pada produksi padi sawah MT ke-1, petani masih bisa mengatasi hama dan penyakit tersebut dengan bantuan Insektisida dan Fungisida.

Pada produksi padi sawah ke-2, petani kesulitan mengendalikan penyakit yang disebabkan oleh jamur Pyricularia grisea. Penyakit blas yang menyerang pada bagian daun dapat berkembang dengan cepat sehingga kematian pada tanaman tidak bisa dihindari. Penyakit blas yang menyerang pada bagian leher malai dapat menyebabkan leher putus atau membusuk sehingga bulirbulir padi hampa. Penyakit yang disebabkan oleh jamur ini merupakan salah satu faktor petani mengalami gagal panen.

Petani yang berada di sektar area pertambangan turut merasakan dampak dari adanya limbah batu bara yang mengalir ke beberapa persawahan. Tingkat keasaman tanah yang tinggi membuat kualitas tanah menurun dan berdampak pada produksi padi sawah yang mempengaruhi pendapatan petani.

Untuk komparasi, hasil penelitian yang dilaporkan oleh Dharmaningtyas (2011) dalam pola rotasi jagung-padi-kacang tanah, rata-rata penerimaan petani adalah Rp.7.263.030,18/ha/thn dengan rata-rata biaya budidaya adalah Rp.22.620.990,51/ha/thn, maka pendapatan rata-rata tahunan sebesar Rp.4.642.039,66/ha.thn. Pada usahatani pola rotasi padi-padi-padi, rata-rata penerimaan adalah Rp.37.576.415,92/ha/thn dengan ratarata biaya yang dikeluarkan adalah Rp.32.133.117,24/ha/thn, sehingga pendapatan rata-rata sebesar Rp.5.443.298,69/ha/thn.

\section{KESIMPULAN DAN SARAN}

\section{Kesimpulan}

Berdasarkan hasil penelitian dan pembahasan dapat diambil kesimpulan sebagai berikut :

1. Rata-rata biaya produksi pada MT ke 1 rata-rata sebesar Rp7.709.156,79/ha/mt adalah lebih tinggi dari MT ke 2 yaitu sebesar Rp6.080.577,02/ha/mt dengan rata-rata per tahun sebesar Rp13.789.733,81/ha/thn.

2. Rata-rata produksi pada MT ke 1 sebesar $1.393,24 \mathrm{~kg}$ adalah lebih tinggi dari MT ke 2 hanya sebesar $642,35 \mathrm{~kg}$ dengan rata-rata produksi per tahun sebesar $2.035,59 \mathrm{~kg}$.

3. Rata-rata penerimaan pada MT ke 1 sebesar Rp9.100.142,97/ha/mt adalah lebih tinggi dari MT ke 2 hanya sebesar $\mathrm{Rp} 4.639 .236,11 / \mathrm{ha} / \mathrm{mt}$ dengan rata-rata penerimaan per tahun sebesar Rp13.284.406,05/ha/thn.

4. Rata-rata pendapatan usahatani padi sawah pola tanam padi-padi adalah $\mathrm{Rp}$ $505.327,76 / \mathrm{ha} / \mathrm{thn}$ dengan rata-rata pendapatan dari MT ke 1 sebesar Rp1.390.986,19/ha/mt dan MT ke 2 sebesar Rp-2.260.029,63/ha/mt.

\section{Saran}

Untuk petani, sebaiknya dalam kegiatan usahatani terutama wilayah sawah dekat dengan aktivitas tambang batu bara bisa menggunakan kapur dolomit agar keseimbangan atau $\mathrm{pH}$ tanah tidak asam. Sehingga tidak mempengaruhi hasil panen dan mengurangi kemungkinan gagal panen. 


\section{DAFTAR PUSTAKA}

BPS Indonesia. 2018. Ekspor Impor. BPS Indonesia.

https://www.bps.go.id/subject/8/ekspor -impor.html\#subjekV iewTab5.

BPS Kab. Kutai Kartanegara. 2020. Kecamatan Loa Kulu dalam Angka 2020. In Badan Pusat Statistik Kabupaten Kutai Kartanegara (Vol. 11, Issue 3). https://www.mculture.go.th/mculture_t h/download/king9/Glossary_about_HM King_Bhumibol_Adulyadej's_Funeral .pdf.

BPS Provinsi Kalimantan Timur. 2021. Provinsi Kalimantan Timur Dalam Angka (Kalimantan Timur Province in Figures) 2021 (Bidang Integrasi Pengolahan dan Diseminasi Statistik (ed.)). BPS Provinsi Kalimantan Timur.

Dharmaningtyas, K. S. 2011. Analisis Perbedaan Pendapatan Antara Usahatani Pola Rotasi Jagung-PadiKacang Tanah Dengan Usahatani Pola Rotasi Padi-Padi-Padi Pada Lahan Sawah Di Kabupaten Sukoharjo. Universitas Sebelas Maret.

Hambali, A., \& Lubis, I. 2015. Evaluasi Produktivitas Beberapa Varietas Padi. Buletin Agrohorti, 3(2), 137-145. https://doi.org/10.29244/agrob.v3i2.154 $\underline{96}$

Indah, L. S. M., Zakaria, W. A., \& Prasmatiwi, F. E. 2015. Analisis Efisiensi Produksi Dan Pendapatan Usahatani Padi Sawah Pada Lahan Irigasi Teknis Dan Lahan Tadah Hujan Di Kabupaten Lampung Selatan. Jurnal Ilmu-Ilmu Agribisnis, 3(3), 268-276.

Munawaroh, S. 2015. Tingkat Pemahaman Gender Pada Rumah Tangga Petani Padi Sawah (Oryza sativa L.) Di
Kelurahan Bukit Biru Kecamatan Tenggarong Kabupaten Kutai Kartanegara.Universitas Mulawarman.

S, T. P. A., Wijayanti, T., \& Widuri, N. 2020. Analisis Pendapatan Usahatani Padi ( Oriza Sativa L .) Sawah di Sekitar dan Bukan Sekitar Tambang Batu Bara di Desa Kerta Buana Kecamatan Tenggarong Seberang Kabupaten Kutai Kartanegara. Jurnal Pertanian Terpadu, 8(1), 62-75.

Salminah. 2018. Analisis Pendapatan Usahatani Padi Sawah di Desa Teratak Kecamatan Muara Kaman Kabupaten Kutai Kartanegara. Universitas Mulawarman.

Saninov, A. A., Alamsyah, Z., \& Suryani, M. 2012. Optimasi Pola Tanam Hortikultura Di Desa Rantau Makmur Kecamatan Berbak Kabupaten Tanjung Jabung Timur. Jurnal Ilmiah SosioEkonomika Bisnis, 15(2), 1-8. https://doi.org/10.22437/jiseb.v15i2.27 $\underline{49}$

Satoto, Widyastuti, Y., Susanto, U., \& Mejaya, M. J. 2013. Perbedaan Hasil Padi Antarmusim di Lahan Sawah Irigasi. Iptek Tanaman Pangan, 8(2), 55-61.

Usman, Z., Made, U., \& Adrianton. 2014. Pertumbuhan Dan Hasil Tanaman Padi (Oryza Sativa L.) Pada Berbagai Umur Semai Dengan Teknik Budidaya Sri (System Of Rice Intensification). $J$ Agrotekbis, 2(1), 32-37.

Yunanda, A. P., Fauzi, A. R., \& Junaedi, A. 2013. Pertumbuhan dan Produksi Padi Varietas Jatiluhur dan IR64 pada Sistem Budidaya Gogo dan Sawah. Buletin Agrohorti, 1(4), 18-25. http://journal.ipb.ac.id/index.php/bulagr on/article/view/8205/pdf, 